\title{
Social Acceptance for Patients Infected with Human Immunodeficiency Virus in Kerman and Rafsanjan, Iran
}

\author{
Reza Bidaki, ${ }^{1,2}$ Zahra Rajabi, ${ }^{3}$ Mohsen Rezaeian, ${ }^{4}$ Masoud Sabouri Ghannad,,${ }^{5}$ and Mohammad \\ Hossein Salehi Shahrbabaki ${ }^{3}$ \\ ${ }^{1}$ Research Center of Addiction and Behavioral Sciences, Shahid Sadoughi University of Medical Sciences, Yazd, Iran \\ ${ }^{2}$ Diabetes Research Center, Shahid Sadoughi University of Medical Sciences, Yazd, Iran \\ ${ }^{3}$ Rafsanjan University of Medical Sciences, Rafsanjan, IR Iran \\ ${ }^{4}$ Department of Social Medicine and Environmental Research Center, Medical School, Rafsanjan University of Medical Sciences, Rafsanjan, IR Iran \\ ${ }^{5}$ Department of Microbiology, Research Center for Molecular Medicine, Medical School, Hamadan University of Medical Sciences, Hamadan, IR Iran \\ "Corresponding author: Masoud Sabouri Ghannad, Department of Microbiology, Research Center for Molecular Medicine, Medical School, Hamadan University of Medical \\ Sciences, P. O. Box: 6517838736, Hamadan, IR Iran. Tel/Fax: +98-8118380208, E-mail: ed_bazrafshan@yahoo.com
}

Received 2015 June 06; Revised 2016 January 11; Accepted 2016 January 13.

\begin{abstract}
Background: Social acceptance in patients with HIV/AIDS is defined as the supports and aids offered by the community around them, which often leads to a better prognosis. If social acceptance is found significantly lower in HIV/AIDS-positive patients, proper planning can be designed to increase the knowledge, awareness and cultural level of society to promote patient acceptance.

Objectives: This research was designed to determine social acceptance in patients infected with HIV/AIDS, referred to the health center of Rafsanjan and the behavioral consultation center in Kerman, Iran, in 2013.

Patients and Methods: In this cross-sectional study, 130 HIV/AIDS-infected patients were enrolled. They filled in the Marlowe-Crowne social acceptance questionnaire and their answers were evaluated according to the questionnaire key. The scores were calculated with statistical t-test and analyzed by SPSS software version 16.

Results: Ninety $(74.6 \%)$ patients were male and $33(25.4 \%)$ were female. They were in the age range of $20-60$ years old. Fifty four (41.5\%) patients had moderate social acceptance and 76 (58.5\%) had high social acceptance scores.

Conclusions: Among the variables including age, gender, education, occupation, residential area, marital status, family history of HIV/AIDS, family history of psychiatric disorders, and CD4 lymphocytes count, the relationship between gender, familial history of psychiatric disorders and CD4 lymphocytes count on one hand and the social acceptance on the other hand were significant (P value $<0.05)$. It means that males with a family history of psychological disorders and patients with high CD4 lymphocytes count level had less social acceptance than others.
\end{abstract}

Keywords: HIV/AIDS, Social Acceptance, Consult Center

\section{Background}

Acquired immunodeficiency syndrome(AIDS) is one of the most influential and contagious diseases that continues to be a threat to the world's population today (1). With regard to the centers for disease control report, more than 1178350 people aged 13 or older have been reported living with AIDS in the United States (2). Social acceptance includes help and support of people in the community that consists of family, friends, neighbors and colleagues. Lack of social acceptance acts as a major obstacle to implementing HIV prevention programs and is considered as a barrier to the HIV/AIDS adoption of medications (3). Although the global spread of HIV/AIDS infection seems complex, it is clear that the lack of social acceptance of people living with HIV and AIDS (PLHIV) is considered as a major barrier to HIV/AIDS care, support and prevention programs $(4,5)$. There are also growing concerns about intolerance toward those with HIV worldwide (6-8). Some studies have confirmed the role of various personal and social factors related to the social acceptance of PLHIV including age, gen- der, education, etc. (9). Moreover, the social acceptance of PLHIV depends on a range of multiple-level psychosocial determinants such as knowledge of HIV/AIDS transmission $(10,11)$.

\section{Objectives}

The main aim of the current research was to determine the social acceptance rate in PLHIV in health centers of Rafsanjan as well as in behavioral consultation center in Kerman, Iran, in 2013.

\section{Patients and Methods}

\subsection{Study Population}

This was a cross-sectional study conducted on PLHIV who had records in health care centers of Rafsanjan as well as in behavioral consultation center of Kerman. 


\subsection{Sampling Method}

Our research protocol was explained to the participants and they signed written consent forms; as a result, HIV-positive patients were enrolled with personal satisfaction. Patients' ages and the period of infection were included in the questionnaire and no questions were left unanswered. The total number of patients in these two centers was 215 , of which 130 (60.4\%) completed the questionnaire. A Persian translation version of the MarloweCrowne questionnaire based on the Marlowe-Crowne social acceptance scale was used in this study, which is one of the most socially acceptable measurement scales. It included 33 questions with two options, yes or no, which indicated that the patients either agreed or disagreed with each phrase (3). To match up the results with the answer keys for each person's scale, the responses were compared to a scale key to determine each individual's score. Scores 0 - 8 indicated a possible lack of social acceptance by the people and therefore, there was a risk of exclusion from the society. Scores 9 - 19 showed the average social acceptance of the patients' behavior, which was according to the policy of social behaviors. Scores 20 - 33 indicated that the actual behaviors of individuals were very compatible with the cultural rules of the society which resulted in the high social acceptance.

\subsection{Data Analysis}

The sociodemographic variables in this research included patient's age, gender, education, occupation, residential area, marital status, family history of HIV/AIDS, family history of psychological disorders, and CD4 lymphocytes count in the current research (2). The recorded social acceptance scores were then evaluated and calculated out of 20 scores. The specific data of patients was analyzed by Statistical Package for Social Sciences (SPSS) version 16. In this study, chi-squared (2) and t-tests were used to evaluate the associations between different parameters and the P value less than 0.05 was considered significant.

\section{Results}

One hundred and thirty patients completed the Marlow-Crowne scale social acceptance questionnaire in the two centers, which included $97(74.6 \%)$ males. Forty (30.8\%) patients had referred to Rafsanjan Health Center and 90 (69.2\%) filled in the questionnaires at the Behavioral Consultation Center in Kerman, Iran, in 2013.

Of 120 (92.3\%) patients who lived in urban areas, 51 (42.5\%) and 69 (57.5\%) had moderate and high social acceptance, respectively. Ten patients lived in rural areas which included $3(30 \%)$ with moderate and 7 (70\%) with high social acceptance $(\mathrm{P}$ value $=0.337)$. Ninety seven patients were male including 45 (46.4\%) with moderate and $52(53.6 \%)$ with high social acceptance. Of 33 female patients, $9(27.3 \%)$ and $24(72.7 \%)$ had moderate and high social acceptance, respectively. Fisher's exact test showed a statistically significant difference between social acceptance of patients and gender $(\mathrm{P}$ value $=0.041)($ Table 1$)$. In view of the family history of psychiatric disorders, among 31 people who had a family history of psychological disorders, 10 (32.3\%) and 21 (67.7\%) had high and moderate social acceptance, respectively (Table 1). Ten patients worked as employees of non-governmental organizations, including 19 (38\%) with moderate and 31 (62\%) with high social acceptance. Six patients were employed in governmental organizations including 1 (16.7\%) with moderate and 5 (83.3\%) with high social acceptance. Seventeen patients were unemployed including 6 (35.3\%) with moderate and 11 (64.7\%) with high social acceptance $(\mathrm{P}$ value $=0.31)$.

In our research, the age average of moderate social acceptance was $41.17 \pm 7.75$ and the age average of PLHIV with high social acceptance was $39.81 \pm 8.72(\mathrm{P}$ value $=0.363$ ).

The mean and standard deviation of the number of CD4 lymphocytes in patients with moderate and high social acceptance was $314.99 \pm 5.71$ and $291.19 \pm 3.95$, respectively $(\mathrm{P}$ value $=0.002)($ Table 1$)$.

\section{Conclusions}

The results showed that accepting attitudes toward PLHIV was significantly associated with gender. The greater social acceptance of females than males may be due to the entrance of more females into universities and high levels of education, knowledge, and social relations in the last decades in Iran. In contrast, additional studies conducted in Tanzania, Namibia and Kenya indicated that higher levels of depressive symptoms were associated with being female (12). Another study indicated that males experienced greater acceptance than females (13). Moreover, a research conducted by Bidaki and colleagues in 2013 in Yazd, another province in Iran (14) (under publication) indicated that the average score for social acceptance was higher for males than it was for females. Our finding about the effects of individual-level variables is not consistent with our previous study in this area (14). This was possibly be due to the low number of females involved in that study (14) However, another research project in Tehran, Iran did not reveal any main differences between males and females regarding social support (15).

High social acceptances were recorded in rural (70\%) and urban areas (57.5\%), respectively, but the difference was not statistically significant. This was not as the expected response. The results may be due to the growing awareness 
Table 1. The Relationship Between Social Acceptance of People Living With HIV and Multiple Variables in Kerman Health Center and Rafsanjan Behavioral Consultation Center in 2013

\begin{tabular}{|c|c|c|c|c|}
\hline Variables & $\begin{array}{c}\text { Moderate Social Acceptance, No. (\%) / } \\
\text { Average } \pm \text { SD }\end{array}$ & $\begin{array}{l}\text { High Social Acceptance, No. (\%) / } \\
\text { Average } \pm \text { SD }\end{array}$ & Total Number & P Value \\
\hline Residential area & & & & 0.337 \\
\hline Urban & $51(42.5 \%)$ & $69(57.5 \%)$ & $120(100 \%)$ & \\
\hline Rural & $3(30 \%)$ & $7(70 \%)$ & $10(100 \%)$ & \\
\hline Gender & & & & 0.041 \\
\hline Male & $45(46.4 \%)$ & $52(53.6 \%)$ & $97(100 \%)$ & \\
\hline Female & $9(27.3 \%)$ & $24(72.7 \%)$ & $33(100 \%)$ & \\
\hline Family history of psychiatric disorders & & & & 0.001 \\
\hline Positive family history & $21(67.7 \%)$ & $10(32.3 \%)$ & $31(100 \%)$ & \\
\hline Negative family history & $33(33.3 \%)$ & $66(66.7 \%)$ & $99(100 \%)$ & \\
\hline Level of education & & & & Not valid \\
\hline Illiterate & $2(33.3 \%)$ & $4(66.7 \%)$ & $6(100 \%)$ & \\
\hline Primary school & $14(43.8 \%)$ & $18(56.2 \%)$ & $32(100 \%)$ & \\
\hline Secondary school & $20(41.7 \%)$ & $28(58.3 \%)$ & $48(100 \%)$ & \\
\hline High school & $15(41.7 \%)$ & $21(58.3 \%)$ & $36(100 \%)$ & \\
\hline Graduate school & $3(37.5 \%)$ & $5(62.5 \%)$ & $8(100 \%)$ & \\
\hline Occupation & & & & 0.31 \\
\hline Labor & $11(57.9 \%)$ & $8(42.1 \%)$ & $19(100 \%)$ & \\
\hline Housewife & $7(35 \%)$ & $13(65 \%)$ & $20(100 \%)$ & \\
\hline $\begin{array}{l}\text { Non-governmental organizations } \\
\text { employee }\end{array}$ & $19(38 \%)$ & $31(62 \%)$ & $50(100 \%)$ & \\
\hline $\begin{array}{l}\text { Governmental organizations } \\
\text { employee }\end{array}$ & $1(16.7 \%)$ & $5(83.3 \%)$ & $6(100 \%)$ & \\
\hline Unemployed & $6(35.3 \%)$ & $11(64.7 \%)$ & $17(100 \%)$ & \\
\hline Farmer & $11(57.9 \%)$ & $8(42.1 \%)$ & $19(100 \%)$ & \\
\hline Duration of HIV infection, $y$ & & & & 0.536 \\
\hline $0-5$ & $28(41.2 \%)$ & $40(58.8 \%)$ & $68(100 \%)$ & \\
\hline $6-16$ & $26(41.9 \%)$ & $36(58.1 \%)$ & $62(100 \%)$ & \\
\hline \multicolumn{5}{|l|}{ Marital status } \\
\hline Single & $23(48.9 \%)$ & $24(51.1 \%)$ & $47(100 \%)$ & \\
\hline Married & $22(38.6 \%)$ & $35(61.4 \%)$ & $57(100 \%)$ & \\
\hline Widowed & $3(37.5 \%)$ & $5(62.5 \%)$ & $8(100 \%)$ & \\
\hline Divorced & $6(33.3 \%)$ & $12(66.7 \%)$ & $18(100 \%)$ & \\
\hline Age & $41.17 \pm 7.75$ & $39.81 \pm 8.72$ & - & 0.363 \\
\hline CD4 & $291.19 \pm 3.94$ & $314.99 \pm 5.71$ & - & 0.002 \\
\hline
\end{tabular}

about AIDS in both rural and urban areas. In contrast, a study conducted in Thailand discovered that the social acceptance was lower in rural than urban areas (16).

In our research, social acceptance of PLHIV did not have any correlation with the job. Nevertheless, a study in Tehran, Iran showed that patients with higher monthly revenue had higher total social acceptance (15). An earlier research in china declared that unemployment was accounted as a risk determinant for suicidal ideation in such patients (17). In addition, a study in Ethiopia reported the 
role of having job in the improvement of life and social acceptance in PLHIV (17).

In the current study, patients with negative family histories of psychiatric disorders had significantly higher social acceptance than patients with positive family histories. Perhaps the stigma of mental diseases in these families interferes with their ability to engage in social communication throughout the course of their illness and accounts as an important determinant in reducing their social acceptance.

Also, CD4 lymphocytes count in PLHIV was associated with their social acceptance. Our findings are not consistent with the report of a research declaring that CD4 lymphocyte counts were not significantly associated with quality of life (18).

Our results should be interpreted within the importance of gender, familial history of psychological disorders and CD4 lymphocytes count in social acceptance. Further investigations need to gain a better consideration of these accepting perspectives toward PLHIV and respond faster to the psychosocial effects of PLHIV. Programmatic strategies will need to consider both community and individual level factors to increase the accepting attitudes in the society.

\section{Acknowledgments}

We appreciate all the staff of the behavioral consultation center in Kerman and Rafsanjan cities for their cooperation.

\section{References}

1. Ghannad MS, Arab SM, Mirzaei M, Moinipur A. Epidemiologic study of human immunodeficiency virus (HIV) Infection in the patients referred to health centers in Hamadan province, Iran. AIDS Res Hum Retroviruses. 2009;25(3):277-83. doi: 10.1089/aid.2008.0143. [PubMed: 19271971].

2. Perkins EL, Stennis KB, Taylor Spriggs V, Kwegyir-Afful EA, Prather A. Is Knowledge Enough? Considering HIV/AIDS Risk Behaviors and HIV/AIDS Knowledge with African American Women. Int J High Risk Behav Addict. 2014;3(3):15038. doi: 10.5812/ijhrba.15038. [PubMed: 25593891].

3. Burgoyne RW, Saunders DS. Perceived support in newly registered HIV/AIDS clinic outpatients. AIDS Care. 2000;12(5):643-50. doi: 10.1080/095401200750003815. [PubMed: 11218549].
4. Malcolm SE, Ng JJ, Rosen RK, Stone VE. An examination of HIV/AIDS patients who have excellent adherence to HAART. AIDS Care. 2003;15(2):251-61. doi: 10.1080/0954012031000068399. [PubMed: 12856346].

5. Peretti-Watel P, Spire B, Obadia Y, Moatti JP, Vespa Group . Discrimination against HIV-infected people and the spread of HIV: some evidence from France. PLoS One. 2007;2(5):ee411. doi: 10.1371/journal.pone.0000411. [PubMed: 17476333].

6. Danziger R. Discrimination against people with HIV and AIDS in Poland. BMJ. 1994;308(6937):1145-7. [PubMed: 8173458].

7. Mimiaga MJ, Closson EF, Thomas B, Mayer KH, Betancourt T, Menon $S$, et al. Garnering an in-depth understanding of men who have sex with men in Chennai, India: a qualitative analysis of sexual minority status and psychological distress. Arch Sex Behav. 2015;44(7):2077-86. doi: 10.1007/s10508-014-0369-0. [PubMed: 25358949].

8. Johnson OE. Social impact of HIV/AIDS on clients attending a teaching hospital in Southern Nigeria. SAHARA J. 2012;9(2):47-53. doi: 10.1080/17290376.2012.683578. [PubMed: 23237039].

9. Vignes M. Health care organisation and chronic disease. A mobilitybased approach. Sante Publique. 2015;27(1 Suppl):23-9. [PubMed: 26168614].

10. Bharat S. Facing the HIV / AIDS challenge: a study on household and community responses. Health Millions. 1998;24(1):15-6. [PubMed: 12348525] 19.

11. Lau JT, Tsui HY, Chan K. Reducing discriminatory attitudes toward people living with HIV/AIDS (PLWHA) in Hong Kong: an intervention study using an integrated knowledge-based PLWHA participation and cognitive approach. AIDS Care. 2005;17(1):85-101. [PubMed: 15832836].

12. Seth P, Kidder D, Pals S, Parent J, Mbatia R, Chesang K, et al. Psychosocial functioning and depressive symptoms among HIV-positive persons receiving care and treatment in Kenya, Namibia, and Tanzania.Prev Sci. 2014;15(3):318-28. doi:10.1007/s11121-013-0420-8. [PubMed: 23868419].

13. Chandrasekaran V, Krupp K, George R, Madhivanan P. Determinants of domestic violence among women attending an human immunodeficiency virus voluntary counseling and testing center in Bangalore, India. Indian J Med Sci. 2007;61(5):253-62. [PubMed: 17478955].

14. Chidwick A, Borrill J. Dealing with a life-threatening diagnosis: the experience of people with the human immunodeficiency virus. AIDS Care. 1996;8(3):271-84. doi: 10.1080/09540129650125704. [PubMed: 8827120].

15. Faraji E, Sardashti S, Firouzeh MM, Aminabad FJ, Alinaghi AS, Hajiabdolbaghi M. Perceived social support affects disease coping among people living with HIV: a study in Tehran, Iran. Asian Pacific JTrop Dis. 2015;5(5):412-7. doi: 10.1016/s2222-1808(14)60806-9.

16. Nyblade L, Pande R, Mathur S, MacQuarrie K, Kidd R, Banteyerga H. Disentangling HIV and AIDS Stigma in Ethiopia, Tanzania and Zambia. Int Center Res Women. 2003.

17. Jin H, Hampton Atkinson J, Yu X, Heaton RK, Shi C, Marcotte TP, et al. Depression and suicidality in HIV/AIDS in China. $J$ Affect Disord. 2006;94(1-3):269-75. doi: 10.1016/j.jad.2006.04.013. [PubMed: 16764941].

18. Nicholas PK, Corless IB, Webster A, McGibbon CA, Davis SM, Dolan SE, et al. A behavioral-medicine program in HIV. Implications for quality of life. J Holist Nurs. 2003;21(2):163-78. [PubMed: 12794959]. 